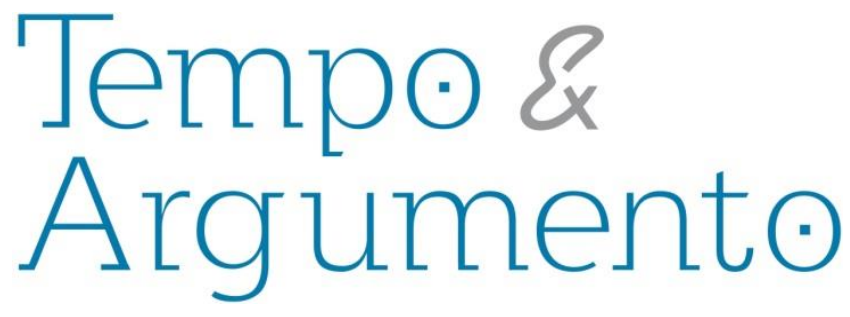

\title{
Afinidades eletivas: a Funarte e o samba carioca como patrimônio da cultura nacional
}

\begin{abstract}
Resumo
Este artigo inventaria e analisa a vasta rede de sociabilidade composta por jornalistas, músicos e produtores culturais envolvidos com a música popular que, no decorrer da segunda metade do século $X X$, ocupando lugares de poder na imprensa escrita, em emissoras de rádios, no mercado fonográfico e em instituições públicas, alcançaram, nos anos 1970 e 1980, negociando com a política cultural do regime militar, monumentalizar artistas e repertórios do universo musical do Rio de Janeiro como patrimônio da cultura nacional. O foco situa-se, especificamente, em dois projetos desenvolvidos pela Divisão de Música Popular da Fundação Nacional de Arte: Lúcio Rangel, concurso de monografias, e Almirante, edição de discos.
\end{abstract}

Palavras-chave: Funarte. Rede de Sociabilidade. Música Popular. Samba. Patrimônio Cultural.

\section{Tânia da Costa Garcia}

Doutor em História Social pela Universidade de São Paulo (USP). Professora Livre Docente do Departamento de História da Universidade

Estadual Paulista (UNESP).

Franca, São Paulo - Brasil garcosta@uol.com.br

\section{Para citar este artigo:}

GARCIA, Tânia. Afinidades eletivas. A Funarte e o samba carioca como patrimônio da cultura nacional. Tempo e Argumento, Florianópolis, v. 9, n. 22, p. 70 - 92, set./dez. 2017.

DOI: $10.5965 / 2175180309222017070$

http://dx.doi.org/10.5965/2175180309222017070 


\title{
Elective affinities: the Funarte and the samba as heritage of national culture
}

\begin{abstract}
This article maps and analyze the vast network of sociability composed of journalists, musicians and producers involved with popular music that, in the second half of the 2oth century, occupying places of power in the written press, radio stations, and in public institutions, managed, in the years of 1970 and 1980, to monumentalize artists and repertoires of the musical universe of Rio de Janeiro as heritage of the national culture. It focus on two projects developed in the Department of Popular Music of the National Art Foundation: Lúcio Rangel, contest of monographies, and Almirante, edition of discs.
\end{abstract}

Keywords: Funarte. Network of Sociability. Popular Music. Samba. Cultural Heritage.

A coroação do samba carioca como "a" música popular brasileira possui, reconhecidamente, uma longa trajetória. Tem início com a escrita memorialística, nos anos 1930 - Na Roda de Samba, de Francisco Guimarães; Samba: sua história, seus poetas, seus músicos e seus cantores, de Orestes Barbosa -, segue, na mesma década, com O Brasil Sonoro, de Mariza Lira; passa pela Revista da Música Popular, editada por Lúcio Rangel, e pelos programas radiofônicos de Almirante, nos anos 1950; e culmina, na década de 1960, com uma nova safra de obras em torno do tema, como Sambista e Chorões, de Lúcio Rangel, Música Popular, um tema em debate, de José Ramos Tinhorão, Panorama da Música Popular Brasileira, de Ary Vasconcelos e No tempo de Noel, de Almirante. Data também da década de 1960 a criação do Museu da Imagem e do Som (MIS), primeira instituição pública, vinculada ao estado da Guanabara, dedicada à museificação do passado musical carioca. Nos anos 1970, durante a ditadura militar, caberia à Fundação Nacional de Arte, especificamente ao Departamento de Música Popular e aos projetos implementados por Hermínio Bello de Carvalho, a coroação do samba carioca como patrimônio da cultura nacional. 
A Fundação Nacional de Arte - criada pela Política Nacional de Cultura, em 1975, atuava, como órgão executivo, em áreas até então sem nenhuma atenção específica por parte do governo': como artes plásticas, música e folclore. De acordo com a legislação, eram atribuições da Funarte:

formular, coordenar e executar programas de incentivos às manifestações artísticas; apoiar a preservação dos valores culturais caracterizados nas manifestações artísticas e tradicionais representativas da personalidade do povo brasileiro; apoiar as instituições culturais oficiais ou privadas que visem ao desenvolvimento artístico nacional (BOTELHO, 2001, p. 63).

Basicamente, suas ações concentravam-se em duas vertentes: a preservação do patrimônio artístico e o incentivo à cultura.

Hermínio Bello de Carvalho - músico, poeta, letrista de canções, autor de livros como O Canto do pajé: Villa Lobos e a música popular brasileira e Cartas cariocas para Mário de Andrade, por quem nutria profunda admiração - transitava no meio musical e intelectual carioca, sobretudo como produtor cultural.

Durante os dez anos em que esteve à frente da Divisão de Música Popular da Fundação Nacional de Arte (Funarte), Carvalho desenvolveu projetos não só com vistas a incentivar nova safra de compositores e intérpretes brasileiros, mas também voltados à monumentalização ${ }^{2}$ de artistas e obras da música popular, perseverando na defesa de uma tradição construída ao longo das décadas anteriores. Nesta empreitada contou com o apoio de uma equipe formada basicamente por jornalistas e pesquisadores cariocas envolvidos com a cultura da cidade, sobretudo com o samba.

A relação entre Carvalho e sua equipe de colaboradores, permeada por aspectos afetivos e ideológicos, antecede aos tempos da Funarte. Embora vários trabalhos acadêmicos venham se dedicando à análise da construção das narrativas que elegeram o

\footnotetext{
1 Setores como o teatro e o cinema já possuíam seus organismos de apoio governamental, como Serviço Nacional de Teatro e a Embrafilme. Sobre a criação da Embrafilme e a política cultural da ditadura militar. Ver Garcia (2007, p. 182-200).

${ }^{2}$ Conforme Le Goff, “(...) o monumento é tudo aquilo que pode evocar o passado, perpetuar a recordação (...)". Parafraseando Paul Zumthor, afirma Le Goff (p. 526): "O que transforma o documento em monumento [monumentalização] é sua utilização pelo poder.” (p. 535)
} 
samba carioca como "a” música popular brasileira, raras ainda são as pesquisas ${ }^{3}$ focadas no destrinchamento das redes de sociabilidade que permitiram que a invenção desta tradição se perpetuasse, influenciando gerações de artistas e intelectuais.

O presente artigo assume o desafio de inventariar e analisar as articulações desta vasta rede de jornalistas, músicos e produtores culturais envolvidos com a música popular que, no decorrer da segunda metade do século $X X$, ocupando lugares de poder - na imprensa escrita, em emissoras de rádios, no mercado fonográfico e em instituições públicas, como o Museu da Imagem e do Som (MIS) e a Funarte - lograram, finalmente, nas brechas da política cultural instituída pelo regime militar, monumentalizar artistas e repertórios do universo musical do Rio de Janeiro como patrimônio da cultura nacional. O foco situa-se, especificamente, no projeto Lúcio Rangel e seus entrelaçamentos com o Projeto Almirante, ambos desenvolvidos por Carvalho e sua seleta equipe na Divisão de Música Popular da Funarte 4 .

Como aporte teórico para esta análise, faço uso das considerações de J. F. Sirinelli em "Os intelectuais", particularmente as noções de itinerário, mapeamento dos territórios de engajamento e rede de sociabilidade, a fim de entender como se articulam os intelectuais em torno da construção, defesa e institucionalização de suas ideias. Ainda em diálogo com o autor, aproprio-me de sua acepção ampla de intelectual, “abrangendo criadores e mediadores culturais". (2003, p. 242)

\section{Hermínio Bello de Carvalho e a política cultural do regime militar}

As relações entre Hermínio Bello de Carvalho com a ditadura militar têm início no período de distensão política, a partir da Sombrás ${ }^{5}$ (Sociedade de Música Brasileira).

\footnotetext{
3 “Anatomia do gosto da Música Popular Brasileira", de Dmitri Fernandes, texto publicado nos Anais do $36^{\circ}$ Encontro Anual da ANPOCS, constitui uma das exceções.

${ }^{4}$ A documentação que suscita e alimenta esta análise foi por mim coletada no CEDOC da FUNARTE, no Rio de Janeiro, em agosto de 2014, constituindo material inédito.

${ }^{5}$ A Sombrás foi fundada em 1974, em consequência da crise de legitimidade das entidades representantes da categoria, SICAM (Sociedade Independente de Autores e Compositores Musicais) e SBACEM (Sociedade Brasileira de Autores, Compositores e Escritores Musicais) - responsáveis, até então, pela arrecadação e regulamentação da cobrança de direitos autorais de compositores e escritores de música.
} 
Como vice-presidente ${ }^{6}$ da organização, trabalhou em prol da moralização da arrecadação dos direitos autorais, pressionando o Ministério da Educação e Cultura a comprar esta causa. Diga-se de passagem, com bons resultados, já que em 1975 era homologado, pelo governo federal, o Conselho Nacional de Direito Autoral (CNDA) e o Escritório Central de Arrecadação (ECAD).

Gozando de certo trânsito na esfera governamental e aproveitando o momento favorável, o vice-presidente da Sombrás, inspirado no sucesso do projeto Seis e Meia ${ }^{7}$, apresentava ao ministro Ney Braga o que seria o futuro Projeto Pixinguinha, inicialmente denominado Um projeto carinhoso (PAVAN, 2006, p. 154).

A proposta foi bem recebida pelo ministro, pelo então presidente da Funarte, João Candido, e pelo diretor da instituição, Roberto Parreira. Um projeto carinhoso teve sua estreia em agosto de 1977, com apresentações em seis capitais: Rio de Janeiro, São Paulo, Porto Alegre, Curitiba, Belo Horizonte e Brasília.

Segundo o biógrafo de Hermínio Belo de Carvalho, Alexandre Pavan, "a filosofia do Projeto Pixinguinha era inspirada nas ideias discutidas na Sombrás: abrir mercado de trabalho ao músico brasileiro, divulgar o repertório nacional de alto nível, ampliar o público e formar novas plateias" (2006, p. 154).

Com o sucesso do Projeto Pixinguinha, Carvalho foi convidado pelo diretor executivo da Fundação Nacional de Arte para ocupar o cargo de consultor de projetos especiais na área de música, terminando, nos anos seguintes, incorporado ao Instituto Nacional de Música como diretor adjunto da Divisão de Música Popular (DMP).

Mas, se por um lado, após anos sem uma política de incentivo para o setor, o regime militar demonstrava disposição em aproximar-se da classe artística ${ }^{8}$, por outro, grupos da sociedade civil já se organizavam em defesa da cultura nacional. Tem início em

\footnotetext{
${ }^{6}$ Seu presidente, no mesmo período, era o compositor Tom Jobim.

7 Criado em 1976 pelo agitador cultural Albino Pinheiro, o projeto Seis e Meia, no seu curto período de vida, levou ao teatro João Caetano, no centro do Rio de Janeiro, no fim do expediente de trabalho, shows de música popular a preços módicos, com grande sucesso de público.

${ }^{8}$ A intenção dos militares era claramente aproximar-se dos setores formadores de opinião - intelectuais, estudantes universitários, artistas - grupo duramente penalizado pela censura nos anos anteriores -, e tentar reverter, perante a sociedade, a imagem desgastada da ditadura, naquele momento piorada com o impacto da crise econômica.
} 
1975 uma série de debates realizados no Teatro Casa Grande, no Rio de Janeiro, envolvendo especialistas no campo do cinema, teatro, música popular, artes plásticas, literatura, jornalismo e publicidade. De acordo com o autor, o tema predominante nesses encontros calorosos era o grave impacto da censura sobre as artes no Brasil e a crescente desnacionalização da vida cultural brasileira (STROUD, 2007, p. 31). Para os participantes, a nossa música estava em crise graças ao controle exercido pelas companhias multinacionais - Odeon, Philips, RCA e CBS - sobre o mercado brasileiro. Se o refluxo da MPB na cena musical era associado à censura, a maneira como as gravadoras resolveram o problema, optando por investir em lançamentos no Brasil de sucessos estrangeiros`, teria colaborado para dificultar o surgimento de novos talentos filiados à sigla.

Um dos desdobramentos desse debate, segundo Sean Stroud, foi a criação, ainda em 1975, em Curitiba, da Associação de Pesquisadores da Música Popular Brasileira (APMPB). Da Associação faziam parte Sérgio Cabral, Ary Vasconcelos, José Ramos Tinhorão, Roberto Moura, Ruy Castro, Tárik de Souza, Zuza Homem de Melo, entre outros - chamo atenção do leitor para esses nomes. Do primeiro encontro resultou o encaminhamento de uma carta para o então ministro do MEC, Ney Braga, propondo, entre outras pautas, reforçar a lei de 1961 que exigia que 50\% da música veiculada no rádio e na TV fosse brasileira. No ano seguinte, no segundo encontro da APMPB, já com aporte da Funarte, o foco da discussão era novamente a ameaça da música estrangeira à cultura nacional e a necessidade de o governo tomar alguma posição em defesa da música popular brasileira (STROUD, 2007, p. 36). A próxima reunião da Associação só ocorreria em 1982, mais uma vez apoiada pela Fundação Nacional de Arte.

Nesse cenário, a Funarte constitui-se como espaço de negociação, em que operavam, de um lado, diretores executivos nomeados pela ditadura militar, e, de outro, gente do meio musical que havia respondido positivamente ao aceno interessado do governo, sem abrir mão de seus projetos e convicções.

Assim, trabalhando oficialmente para a Fundação, Carvalho, na medida do possível, buscou aproximar sua visão de cultura da política cultural que pautava a

\footnotetext{
9 "A transnacional fazia a prensagem, embalagem e distribuição local das matrizes gravadas no exterior, para serem simplesmente comercializada no país, permitindo ao produto chegar ao mercado com seus custos de produção amortizados." Ver DIAS (1991, p. 58).
} 
Funarte. Entre os vários projetos criados e implementados por sua equipe, a partir de 1978, estavam o concurso de monografias, projeto Lúcio Rangel, e o registro em disco de repertórios da música popular brasileira fora do mainstream, projeto Almirante.

O concurso de monografias foi criado na intenção de incentivar a produção sobre a história da música popular brasileira. De acordo com seus idealizadores, era preciso despertar o interesse de novos pesquisadores sobre o tema e incrementar a escassa bibliografia existente. De fato, o número de publicações sobre o assunto era pífio e os poucos livros escritos por memorialistas/jornalistas estavam esgotados há tempos. O projeto Almirante, integrado ao projeto Lúcio Rangel, tinha por objetivo atender ao escoamento de uma produção artística que dificilmente seria absorvida pelo circuito discográfico comercial. O projeto orientou-se por "documentar não só essa produção como também editar e fazer difundir aquele tipo de bem cultural que jamais chegou ao disco, ou que nele teve vida efêmera, objetivando dessa forma reeditar títulos essenciais ao entendimento de nosso processo de criação."10

Não obstante a atuação da Funarte fosse pautada pelo Plano Nacional de Cultura, que tinha como um de seus pilares a "fixação da personalidade cultural do país, em harmonia com seus elementos formadores e regionais" (CALABRE, 2007, p. 92), chama a atenção a maneira singular como este ideário foi, desde o início, apropriado pelos projetos implementados por Hermínio Bello de Carvalho e seus colaboradores. A homenagem póstuma a duas personalidades cariocas, o jornalista Lúcio Rangel e o radialista e pesquisador Almirante, figuras-chave do processo de monumentalização e museificação do samba carioca, já sinalizava o que estava por vir.

\section{No rastro do projeto Lúcio Rangel}

Nos anos de atividade do projeto Lúcio Rangel, praticamente uma década, os editais eram amplamente divulgados em diversos jornais do país. As temáticas ou personagens a serem monografados, anunciados como representantes da música popular brasileira, eram, na sua grande maioria, pertencentes ao universo musical carioca.

\footnotetext{
10 Resumo do projeto Almirante publicado nos encartes que acompanhavam os discos produzidos pela Funarte.
} 
Elaborada por Carvalho e seus colaboradores, a justificativa para a escolha desse elenco tinha como critério "a relevância cultural do assunto ou personagem e o risco de perecimento das fontes"11. O vencedor do concurso receberia um prêmio em dinheiro e, se houvesse mérito, o trabalho seria publicado pela Fundação. Todos os editais exigiam que as monografias explicitassem minuciosamente as fontes utilizadas pelo pesquisador, na intenção de garantir o caráter documental do trabalho. O levantamento completo da discografia, composições gravadas, e daquelas ainda inéditas, não registradas, também era obrigatório.

As comissões organizadas por Carvalho para assessorá-lo eram constituídas por um círculo de relações bastante restrito, formado por jornalistas que atuavam como críticos e historiadores, por pesquisadores/escritores e musicólogos, na sua maioria residentes no Rio de Janeiro. Conforme registrado nas atas das reuniões ${ }^{12}$, não era incomum os participantes das comissões que elaboravam os editais, escolhendo os personagens ou temas a serem monografados, atuarem ainda como membros das comissões julgadoras do mesmo concurso, realizando os pareceres e elegendo os vencedores.

No decorrer do projeto Lúcio Rangel, Hermínio e seus pares vão deixando rastros de uma declarada preferência pela música popular carioca e seus músicos, mais especificamente pelos compositores ligados às tradicionais comunidades das escolas de samba, em detrimento da diversidade da cultura nacional, orientada pela política cultural do regime militar.

Em 1979, com a transição da presidência da república do general Ernesto Geisel para o general João Figueiredo, resultando na saída de Ney Braga (1974-1978) e na entrada de Eduardo Portela como novo ministro de Educação e Cultura, o Departamento de Assuntos Culturais era substituído pela Secretaria de Assuntos Culturais (SEAC). Segundo Botelho, a SEAC "pretendia exercer efetivamente seu papel de supervisora das instituições culturais do ministério (...)", interferindo, dessa forma, na autonomia da

\footnotetext{
${ }^{11}$ Dossiê projeto Lúcio Rangel. Centro de Documentação da Funarte.

${ }^{12}$ Dossiê projeto Lúcio Rangel. Centro de Documentação da Funarte.
} 
Funarte (BOTELHO, 2001, p. 80). A nova Secretaria proporia ainda uma revisão da concepção de cultura presente no Plano Nacional de Cultura.

Em carta manuscrita encaminhada a funcionários da Fundação, Carvalho manifesta seu receio quanto à transição de governo, expondo o tipo provisório de liberdade vivida, garantida muito mais pelas relações pessoais estabelecidas, do que pelas instituições políticas (1978-1979). Recordando o que havia acontecido no MIS, envolvendo nomes que estavam presentes também nas comissões da Funarte, afirma: "O governo está mudando, o Roberto [Parreira] pode de repente não ficar, aí entra o Álvarus (que ao ser empossado no Museu da Imagem e do Som tachou os conselhos de subversivos e os fechou todos) e faz aquela cagada em regra e as ideias da gente sifu." (1978-1979)

De acordo com as observações de Carvalho na carta, as novas diretrizes do PNC preconizavam "uma ação social voltada para a população de baixa renda e para as regiões carentes" (1978-1979). A "identificação comunitária"13 seria o princípio básico da ação proposta pela Secretaria de Assuntos Culturais (SEAC), que intencionava:

fazer o levantamento das características culturais das comunidades, das regiões e do povo em geral. Através desses levantamentos, além de se descobrir incríveis riquezas culturais, onde menos se espera, se descobririam também as grandes motivações da comunidade, que seriam então o componente essencial de um projeto maior de desenvolvimento do país (1978-1979).

Já em 1979, adequando-se às mudanças, o edital lançado para o terceiro concurso do projeto Lúcio Rangel deixava claro, nos itens do roteiro, que as monografias deveriam extrapolar o estritamente biográfico e enfocar o personagem também como produto da cultura da comunidade.

O concurso envolvendo o compositor Candeia, por exemplo, esclarecia que:

O trabalho terá que precisar sua relação com a escola de samba Quilombo; a relação de seu trabalho com a organização de movimentos de grupos negros; a liderança exercida pelo compositor na comunidade, influenciando novos compositores; sua obra situada no panorama da música popular brasileira, do ponto de vista de sua ideologia, de sua

\footnotetext{
${ }^{13}$ Denominação provavelmente utilizada pelo PCN e reproduzida por Carvalho na carta.
} 
linguagem, de suas relações internas e da repercussão alcançada. (Dossiê Projeto Lúcio Rangel. CEDOC/FUNARTE, Rio de Janeiro, 2 de janeiro de 1979)

Sobre Alcebíades Barcelos, o Bide, os itens contemplados pelo edital incluíam:

\begin{abstract}
A importância de sua obra na fixação da linguagem do samba carioca; a história da Deixa Falar, sua organização como escola, seus fundadores; $O$ [bairro] Estácio no samba, os fatos históricos e sociais advindos da proximidade do Estácio com a Praça XI; a repressão e a malandragem em diversos aspectos; e finalmente o Estácio como submercado artístico - a transformação do bairro no primeiro centro de mão de obra sambista. (Dossiê Projeto Lúcio Rangel. CEDOC/FUNATE, Rio de Janeiro, 2 de janeiro de 1979)
\end{abstract}

Carvalho e sua equipe, dominando a história a ser narrada, apresentavam estrategicamente a sua versão de "identificação comunitária", relacionando "a fixação da linguagem do samba" à história da sua comunidade. E, fazendo frente ao discurso de unidade harmônica de nação, homogeneizador de classes, gêneros e etnias, caro ao nacionalismo dos militares, os roteiros valorizavam o movimento negro em oposição à concepção de "cadinho de raças", sugerindo ainda a crítica à atuação disciplinadora do poder sobre a cultura popular.

Em 1980, a comissão que assessorou Hermínio Bello de Carvalho na elaboração do edital foi formada pelos cariocas Sérgio Cabral, Ary Vasconcelos, Roberto Moura, Paulo Tapajós, Maurício Quadrio, Albino Pinheiro, Tárik de Souza, Aloysio Alencar Pinto e o curitibano Aramis Millarch ${ }^{14}$. Os personagens a serem monografados eram: João Pernambuco (João Teixeira Guimarães, 1883 - 1947), Luperce Miranda (1904 - 1977) "e o grupo de mulheres baianas que, com a famosa Tia Ciata à frente, tiveram destacada atuação no processo de fixação das características do samba carioca nos primórdios do século XX" (MILLARCH, 1980, s/p.). Aliás, os três pertenciam à fase de formação e consolidação do que os especialistas do assunto - lê-se, a equipe de Carvalho reconheciam como a música popular brasileira.

\footnotetext{
${ }^{14}$ Ata da reunião realizada na CONPROES nos dias 4 e 5 de fevereiro de 1980. Dossiê Projeto Lúcio Rangel. Centro de Documentação Funarte.
} 
A comissão julgadora desse mesmo concurso foi formada por Ary Vasconcelos, Paulo Tapajós, Tárik de Souza, Albino Pinheiro, Ligia Santos e Ana Maria Bahiana. Entre os vencedores estava o jornalista Roberto Moura, com a obra "Tia Ciata e a pequena África no Rio de Janeiro", publicada pela Funarte em 1983. Em que pese a qualidade inquestionável do trabalho premiado, Moura havia sido membro da comissão responsável pela formulação do edital do seu próprio concurso, conforme ata assinada pelos presentes.

A partir de 1981, a fim de conseguir maiores recursos para o projeto, foi feita uma parceria da Funarte com o Conselho Nacional de Direito Autoral, que, até 1986, patrocinou integralmente todas as premiações, concedendo inclusive bolsas aos pesquisadores $^{15}$. Como forte colaborador, o Conselho endossava a linha de trabalho adotada por Carvalho e sua equipe.

Em 1983, para o edital do concurso sobre Orlando Silva, Ary Vasconcelos, como membro da comissão, propunha o seguinte roteiro:

1) momento histórico em que nasceu, o Rio de Janeiro da segunda década do século $[\mathrm{XX}]$ e os subúrbios cariocas onde Orlando Silva viveu sua primeira infância - o pai José Celestino, violonista, e o panorama geral do choro - A mãe, dono Balbina e o ambiente em casa, os primeiros anos e as primeiras profissões. $O$ acidente aos 16 ano de idade. A vocação de cantor e o primeiro repertório - A estreia no rádio - As primeiras gravações - A fase de ouro de Orlando, quando se torna o cantor das multidões. $O$ encontro com Tito Schipa, seus grandes sucessos no rádio e em discos. Panorama do rádio na época de Orlando Silva. Os filmes de que participou. Excursões, amores, tóxicos. O declínio a partir de 1946 e a reação em 1954. Lps que gravou, depoimentos que prestou para a posteridade. um anjo de guarda chamado Lourdes na vida de Orlando. Últimos anos, a morte, o enterro apoteótico - Cantores que influenciou. (Projeto Lúcio Rangel. Concurso de monografias, pasta 10, 1983/1984).

A trajetória artística de Orlando Silva traçada por Vasconcelos, não por acaso, coincidia com a cronologia dos fatos elencados e narrados pelo autor, em seu livro

\footnotetext{
${ }^{15}$ Em 1982 o Conselho Nacional de Direito Autoral financiou 5 bolsas no valor de 250 mil cruzeiros a serem entregues numa única parcela, aos autores convidados para escreverem as monografias sobre Araci Cortes, Bide, Lupicínio Rodrigues, Nelson Ferreira, Candeia e Luperce Miranda. O propósito era resolver o problema das monografias que, por não alcançarem resultados satisfatórios nos concursos, não puderam ser publicadas, impedindo a posteridade dos monografados.
} 
imprimindo à monografia, que ainda nem sequer existia, sua visão da história, não deixando muitas alternativas para o futuro autor. O roteiro mais detalhado, se, por um lado, evitava lacunas e divagações cometidas por autores muitas vezes inexperientes, por outro resultava no engessamento da narrativa, impedindo qualquer desvio do pesquisador do caminho previamente definido pelo diminuto grupo de especialistas do qual se cercava Carvalho.

Para se ter uma ideia do perfil dos pesquisadores contemplados pelos concursos, cito aqui os vencedores de 1981: Marília Barbosa da Silva e Arthur de Oliveira Filho, ambos cariocas e ligados ao ensino de literatura, ganham o concurso sobre Cartola; Marília já havia sido contemplada pela monografia sobre Paulo Portela, em coautoria com Ligia Santos. Francisco Duarte Silva e Nelson Sargento, também cariocas, sendo o último ligado diretamente ao samba e sua comunidade, vencem o concurso sobre Geraldo Pereira. E um grupo formado por quatro pesquisadores cariocas é o vencedor do concurso sobre Patápio Silva. Portanto, os quatro editais de 1981 são organizados por gente do Rio de Janeiro, versando sobre músicos da mesma cidade e os inscritos, pelo menos os premiados, obedecendo a uma tendência recorrente, eram também cariocas.

Em 1984, a comissão composta por Ary Vasconcelos, João Máximo e Ana Maria Bahiana indicava os seguintes nomes para o concurso de monografia: Ernesto Nazaré, Custódio Mesquita e Ismael Silva - mais uma vez a proposta era a monumentalização de compositores da música popular carioca. A comissão julgadora foi formada por João Máximo, Jairo Severiano e Afonso Henrique Guimarães Neto.

Entre 1977 e 1984, o projeto Lúcio Rangel havia lançado 24 personagens/temas para serem monografados. As monografias que se tornaram livros estão concentradas entre

\footnotetext{
${ }^{16}$ Analisando a obra de Vasconcelos, Marino e Moraes concluem que "O modelo de biografia utilizado por Ary Vasconcelos se enquadra naquele chamado por François Dosse de "vidobra". Trata-se de uma biografia que narra a vida do personagem pura e simplesmente em função de sua obra. Este tipo de construção narrativa foi recorrente nas biografias musicais e artísticas no século XIX, e é também muito comum nos outros historiadores da geração de Ary." Ver MARINO, I. K. e MORAES, José G. V.
} 
1978 e 1985, somando um total de 19 obras. De 1986 a 1988, último período de publicação da coleção Funarte de monografias, foram lançados apenas cinco livros, destes, dois, Yes, nó temos Braguinha e Capiba é frevo, meu bem, não foram objetos de concursos, mas encomendados aos seus autores, respectivamente Jairo Severiano, membro das comissões de Carvalho, e Renato Phaelante da Câmara e Aldo Paes Barreto.

Num balanço geral, chama a atenção na documentação referente aos concursos o baixo número de inscritos. Em 1979, por exemplo, houve três concorrentes para o concurso sobre Dorival Caymmi e mais três sobre Paulo da Portela; para Silas de Oliveira, dois inscritos; para Jararaca e Ratinho, apenas um interessado, e, para Candeia, nenhum. Tal escassez atravessou o projeto Lúcio Rangel do início ao fim. Nos dois últimos concursos, ocorridos respectivamente 1988 e 1989, concorreram para o edital sobre o popular "Clã dos Batista" somente dois pesquisadores. O tema "Do Tropicalismo ao rock" atraiu somente um inscrito, assim como "Herivelto Martins". "Os regionais brasileiros" não despertou nenhum interesse. Sobre "João Gilberto" e "Marlene e Emilinha" também não houve nenhum inscrito. "Jacob do Bandolim" e "Isaurinha Garcia" tiveram um inscrito cada um.

As prováveis razões para esse baixo retorno são reconhecidas pelo próprio grupo de especialistas responsável pelos editais. Sobre os personagens pautados para o concurso de 1981, ressaltava o folheto de divulgação: “Alguns são bem conhecidos, como Cartola e Araci Cortes, outros dois; Geraldo Pereira, não é totalmente estranho, mas Patápio Silva, o extraordinário flautista do começo do século, só é familiar aos especialistas de MPB"17 - deixando subentendido que haveria nesse "esquecimento" mais um motivo para que se prestasse a homenagem. Há casos extremos em que o músico a ser monografado, com pouca projeção fora dos limites da sua comunidade, demandava dos pesquisadores outras estratégias, como a aproximação dos familiares, amigos e parceiros musicais. Esse foi o caso da monografia vencedora do concurso sobre Paulo da Portela, escrita por Marília T. Barbosa da Silva e Ligia Santos. Ligia, filha de Donga, era figura conhecida na comunidade, o que facilitou o estabelecimento de uma

\footnotetext{
${ }^{17}$ Folheto de divulgação do concurso de monografias de 1981. Dossiê projeto Lucio Rangel Centro de Documentação da FUNARTE.
} 
Outro aspecto que certamente limitava o número de interessados era o financeiro. O pesquisador teria que se autocustear e ainda correr o risco de "perda total", já que somente um dos concorrentes seria contemplado pelo prêmio.

Problema recorrente era também a qualidade dos trabalhos apresentados. Nem sempre era possível escolher um vencedor, no entanto, de acordo com o edital, era preciso conceder o prêmio, eximindo-se do compromisso de publicar a monografia, como aconteceu com o ganhador do concurso sobre Lupicínio Rodrigues ${ }^{18}$.

Vários foram, portanto, os percalços enfrentados pelo concurso de monografias, o que não intimidou seus idealizadores. Conhecidos de longa data, haviam estado juntos em inúmeras outras ocasiões em ações em prol da preservação e perpetuação do que defendiam ser a música popular brasileira. Desta vez, ocupando lugar estratégico na esfera de poder, mesmo que a contrapelo, não abriram mão de finalmente alçar o samba carioca à condição de patrimônio da cultura nacional.

\section{Inventariando solidariedades}

Dentre os nomes mais recorrentes nos processos de formulação dos editais e presentes nas comissões de julgamento das monografias do projeto Lúcio Rangel -Ary Vasconcelos, Albino Pinheiro, Sérgio Cabral, Paulo Tapajós, Lúcio Rangel (falecido em 1979, participa apenas no primeiro ano), João Máximo, Jairo Severiano, Tárik de Souza, Roberto Moura, Ana Maria Bahiana e o curitibano Aramis Millarch -, quase todos atuavam como jornalistas e críticos da música popular, elegendo com sua pena o que era digno ou não de se tornar assunto na imprensa, lido e comentado pelos leitores dos principais jornais do país. Alguns, como Rangel, Vasconcelos, Cabral e Moura, reconhecendo a vida curta do jornalismo impresso, investiram na escrita de obras mais

\footnotetext{
${ }^{18}$ Fugindo à regra, nove foram os concorrentes para o concurso sobre o compositor Lupicínio Rodrigues, no entanto, não rendeu nenhum trabalho de mérito. Houve sim um vencedor que foi contemplado com a premiação, mas sua monografia não foi publicada.
} 
Desta segunda geração de historiadores e/ou memorialistas da nossa música ${ }^{19}$, alguns ocuparam lugares estratégicos de poder, como produtores de discos em gravadoras, jurados de concursos, como os festivais da canção da década de 1960, e foram membros de conselhos e comissões de instituições públicas, como o Museu da Imagem e do Som e a própria Funarte.

O carioca Ary Vasconcelos constitui um exemplo típico deste perfil. Jornalista sempre ligado ao universo da música popular e autor de diversos livros sobre o assunto, atuou como júri dos citados festivais, trabalhou para a indústria fonográfica, especificamente para a Odeon, produziu programas sobre a História da MPB na rádio MEC, e foi membro, ao lado de outros citados aqui, de conselhos de museus e fundações ligados à música popular, como o MIS e a Funarte, e a Associação de Pesquisadores da Música Popular Brasileira. Vasconcelos foi ainda autor de diversos livros sobre o tema que conhecia. Dos seis publicados, destaco Panorama da Música Popular Brasileira, de 1964. Como o próprio título informa, numa abordagem panorâmica, divide a história de nossa música popular em três momentos da história do Brasil - colônia, império e república - e nomeia o período entre 1927 e 1946 de fase de ouro, deixando clara sua preferência pelos compositores, cantores e repertório inseridos nesse recorte temporal. Para Vasconcelos, na denominada "fase de ouro" estaria situada a genuína música popular urbana que, nas décadas seguintes, assediada pelo mercado, se teria deixado corromper, sofrendo ainda influências deturpadoras com a invasão da música estrangeira, sobretudo durante e após a segunda Grande Guerra.

Lúcio Rangel, cujo nome em homenagem póstuma foi atribuído ao projeto de monografias, teve atuação breve como membro das comissões instituídas por Carvalho na Divisão de Música Popular da Fundação. Com trajetória profissional na imprensa

\footnotetext{
${ }^{19}$ Conforme Jose Geraldo Vinci de Moraes, a primeira geração de historiadores da música popular brasileira é composta por Francisco Guimarães (Vagalume), autor de Na Roda do Samba, por Orestes Barbosa, Samba: sua história, seus poetas, seus músicos e seus cantores, ambas publicadas em 1933, Choro, de Alexandre Gonçalves Pinto, lançada em 1936, e Brasil Sonoro de Mariza Lira. Ver MORAES (2007).
} 

assunto, tinha o propósito claro de valorização de compositores e repertórios urbanos, situados nas primeiras décadas do século XX, circunscritos basicamente ao Rio de Janeiro, coincidindo com o período cunhado por Ary Vasconcelos de "fase de ouro". A revista constituía uma espécie de frente de resistência ao processo de massificação em curso nos meios de comunicação, vistos como responsáveis pela descaracterização da "música brasileira de qualidade." Sempre um militante da tradição, no auge da bossa nova, em 1963, Rangel publicou o livro Sambistas e Chorões, numa apologia do samba como a genuína música do povo brasileiro. Ainda nos anos 1960, integrou o Conselho Superior de Música Popular do Museu da Imagem e do Som.

Outro membro das comissões da Funarte com destaque na construção e afirmação de uma dada história sobre a música popular brasileira foi Sérgio Cabral. Cabral trabalhou em diversos diários e revistas do Rio de Janeiro, atuando no Jornal do Brasil como jornalista especializado em música popular. Foi um dos fundadores do teatro Casa Grande, em 1966 - espaço que sediou a série de debates culturais ocorridos em 1975, posicionando a classe artística no processo de redemocratização do país. Foi também fundador e jornalista do Pasquim, época em que chegou a ser detido e preso pela ditadura militar. Atuou ainda como produtor de discos na RCA/Victor e na Polygram. Sérgio Cabral participou como autor do primeiro concurso de monografias promovido pela Funarte, sendo laureado com o prêmio em dinheiro e a publicação, pela Fundação, de Pixinguinha Vida e obra, em 1978. Cabral também foi um dos membros do Conselho Superior da Música Popular do MIS e da APMPB.

João Máximo, jornalista dedicado à área musical e ao esporte, com longa carreira na imprensa carioca, também esteve entre os nomes sempre requisitados por Carvalho para integrar as comissões do projeto Lúcio Rangel. No campo da música popular, em parceria com Carlos Didier, debruçou-se nos anos 1980 sobre a vida de Noel Rosa, resultando na biografia publicada, em 1990, pela editora da Universidade Nacional de Brasília. 
Paulo Tapajós, músico e radialista na década de 1960, pertenceu à comissão executiva do primeiro Festival da Canção e foi membro fundador do Conselho Superior da Música Popular do MIS. Durante a ditadura, esteve ligado ao projeto Minerva, na Rádio do Ministério da Educação e Cultura, além da Divisão de Música Popular da Funarte.

Da equipe formada por Carvalho, dois não eram propriamente oriundos da imprensa ou dos meios de comunicação. Albino Pinheiro, atuando intensamente no ambiente cultural da cidade do Rio de Janeiro, esteve ao lado de Sérgio Cabral e de Hermínio Bello de Carvalho na produção artística do Zicartola. O bar e restaurante, aberto em 1963, reunia a Velha Guarda da música popular carioca, como Nelson Cavaquinho e Clementina de Jesus, ao lado de jovens músicos como Paulinho da Viola, Carlos Lira, Nara Leão, além de intelectuais e estudantes alinhados politicamente à esquerda. Pinheiro foi ainda idealizador e produtor do projeto Seis e meia, precursor e inspirador do projeto Pixinguinha, produzido por Hermínio Bello de Carvalho, na Funarte.

Jairo Severiano, bancário, apaixonado pela música popular e com espírito de colecionador, dedicou-se ao levantamento da discografia brasileira em $78 \mathrm{rpm}$, pesquisa publicada pela Funarte em $1982^{20}$. Severiano está entre os membros da comissão da Funarte que publicou pelo projeto Lúcio Rangel. O livro sobre a trajetória artística do músico Braguinha, Yes, nós temos Braguinha, de 1987, foi encomendado ao autor, que não participou de concurso de monografia. Trabalhando para o Projeto Almirante, também sob a coordenação de Carvalho, produziu os álbuns Araci Cortes, Orlando Silva e Nosso Sinhô do Samba, resultados de regravações dos originais em 78 rpm.

O jornalista Roberto Moura, ao lado de Tárik de Souza e Ana Maria Bahiana, todos cariocas, integravam a ala mais jovem do grupo de colaboradores da Divisão de Música Popular. Publicando artigos no Pasquim e na Tribuna da Imprensa, Moura tornou-se conhecido pelo seu nacionalismo radical em defesa da música popular brasileira e contra a invasão da música estrangeira. Boêmio, foi amigo de músicos e compositores cariocas, chegando a produzir um disco de Sérgio Sampaio, lançado pela Continental em 1976. Vale lembrar que Roberto Moura, como Sérgio Cabral, foi também autor contemplado no

\footnotetext{
${ }^{20}$ Sob o título Discografia Brasileira - 78 RPM-1901/1964, a publicação não integra o Projeto Lúcio Rangel.
} 
concurso do projeto Lúcio Rangel, com a monografia "Tia Ciata e a Pequena África no Rio de Janeiro".

Tárik de Souza, com atuação intensa na imprensa escrita, sempre esteve ligado ao campo musical, trabalhando, na década de 1970, em diversas publicações alternativas, como Opinião, Pasquim e O Movimento. Nesse período também escreveu para o Jornal do Brasil, mantendo a coluna "Supersônicas", em que assinava artigos sobre a cena musical do país. Foi também consultor da coleção História da Música Popular Brasileira, publicada pela Editora Abril, cujos encartes dos discos, escritos por pesquisadores, como José Ramos Tinhorão e Zuza Homem de Melo, reafirmaram a narrativa hegemônica, desde as primeiras décadas do século XX.

Ana Maria Bahiana, uma das poucas mulheres a participar das comissões ${ }^{21}$ constituídas por Carvalho, era jornalista especializada na área cultural. Além de trabalhar nos principais jornais do país, foi crítica de música da revista Rolling Stones brasileira, interferindo na cena musical da MPB e do rock nacional e internacional, no início dos anos 1970. Diferentemente dos demais membros assíduos das comissões, a relação de Ana Maria com o discurso da tradição, ou de defesa da autêntica música popular brasileira, era mais à distância, não militando em prol da causa.

Deste time, com presença marcante nas comissões formadas por Hermínio Bello de Carvalho na Funarte, resta ainda o curitibano Aramis Millarch. Fugindo à regra em termos geográficos, mas não no plano das ideias, Millarch foi membro assíduo das comissões do projeto Lúcio Rangel, enviando suas opiniões e pareceres geralmente por carta. Jornalista muito ativo na área de cultura, trabalhando como crítico de música e cinema, manteve por mais de 30 anos a coluna "Tabloide" no jornal O Estado do Paraná. Nesse espaço Millarch divulgou inúmeras vezes os concursos promovidos pelo projeto Lúcio Rangel. A primeira reunião da APMPB, em 1975, ocorreu em Curitiba, não por acaso terra de Aramis Millarch, um dos fundadores e primeiro presidente da Associação.

\footnotetext{
${ }^{21}$ Lígia Santos e Marília Barbosa da Silva, ambas autoras da premiada monografia Paulo da Portela. Traços de união entre duas culturas, também participaram pontualmente de uma das comissões de trabalho do projeto Lúcio Rangel.
} 
Notoriamente, o grupo de intelectuais que trabalhou com Carvalho no projeto Lúcio Rangel possuía laços que extrapolavam os tempos de Funarte. Organizados em torno de "uma sensibilidade ideológica ou cultural comum" (SIRINELLI, 1996, p. 248), integravam uma rede de relações, estruturada na média duração, em prol do nacionalismo musical, moldando e sendo moldada pelas distintas formas de uso e apropriação das representações do popular atreladas ao nacional, ao longo do século XX. Se o samba carioca foi, em algum tempo, marginal, submetido, pela sua herança negra, às obscuras hierarquias raciais, sua urbanidade nata permitiu-lhe cruzar fronteiras sociais, étnicas e até mesmo ideológicas. Tal transposição foi facilitada pelas redes e microclimas (SIRINELLI, 1996, p. 253) constituídos por estes intelectuais, com trânsito e poder em diferentes circuitos culturais, políticos e sociais.

\section{Breves considerações sobre o projeto Almirante}

O projeto Almirante, operando de forma integrada ao projeto Lúcio Rangel, lançava discos de compositores e intérpretes já monografados ou em vias de o serem. Dentro deste espectro, eram selecionadas majoritariamente obras cujas gravações possuíam registros somente em 78 rotações. Os lançamentos dos discos ocorriam quase sempre um ano após a publicação das monografias, complementando, com a reprodução sonora, a perpetuação destas memórias. Há casos raros de artistas que foram contemplados com um disco, mas não foram monografados, como Herivelto Martins; o compositor Antonio Maria, homenageado pelo projeto Lúcio Rangel com a publicação de uma coletânea de suas crônicas publicadas na imprensa; e Sidney Miller, músico que, embora fuja ao perfil do projeto, recebeu homenagem póstuma de seus colegas da FUNARTE, com disco lançado em 1982. O projeto Lúcio Rangel também tem nomes que não mereceram um disco, como o músico Waldemar Henrique. O Canto da Amazônia, de Claver Filho, e Adoniran Barbosa, um sambista diferente, de Bruno Gomes - não por acaso um amazonense e um paulista num mar de nomes cariocas.

Interessante notar que o projeto Almirante, a despeito da ideia de registrar repertórios em vias de desaparecimento, não levava às últimas consequências a intenção 
de preservar os antigos arranjos e harmonizações. A grande maioria dos discos traz novas gravações para antigos repertórios. Raros são aqueles que, como Jararaca e Ratinho, Araci Cortes, Orlando Silva e Nosso Sinhô do samba, possuem gravações de época. Músicos arranjadores, como Mauricio Carrilho e Henrique Cazes estão presentes em um grande número de $\operatorname{dis} \cos ^{22}$. Considerando que as gravações são mais ou menos próximas, entre os anos 1983 e 1989, é possível afirmar que participam do projeto uma mesma geração de músicos ou pelo menos duas, como o encontro de Radamés e Rafael Rabello, em Tributo a Garoto, e dos intérpretes reunidos em torno dos discos de Cartola e Wilson Batista. Notoriamente os músicos envolvidos com o projeto transitam com conhecimento pelos repertórios do samba e do choro carioca, como sinalizam os arranjos e as interpretações registradas nos discos. Talvez a opção por novas gravações em vez da regravação dos originais tenha intencionado dar uma nova roupagem ao repertório, em busca não só de colecionadores, mas de novos ouvintes, já que muitos desses discos em 78 rpm eram precários em termos sonoros, não fazendo jus à qualidade dos músicos. Também vale considerar a possibilidade de oferecer trabalho aos artistas, aspecto nunca perdido de vista por Carvalho, fiel às suas redes de relações.

O suporte para a registro e difusão foi o disco de vinil de longa duração, o LP, espaço por excelência da música popular do século XX. A maioria dos discos foram prensados pela fábrica Gravações Elétricas S. A., detentora de vários selos, como Continental, Phonodisc, Musicolor entre outros. Seguindo a mesma linha do projeto Lúcio Rangel de preservação da memória, os discos eram acompanhados por encartes, quase livretos, contendo a apresentação do projeto Almirante e longos textos narrando a importância do artista e sua obra para a história da música popular brasileira.

Vale notar que parte dos textos que compunham a "trajetória do artista" era retirada das monografias, reproduzindo o mesmo discurso orientado pelos roteiros dos editais do projeto Lúcio Rangel. Jairo Severiano, provavelmente em função de seu vasto conhecimento sobre o repertório da música popular brasileira registrado em $78 \mathrm{rpm}$, também assina vários deles como autor.

\footnotetext{
${ }^{22}$ Grande parte da coleção de discos do Projeto Almirante, contendo imagens das capas e encartes para consulta, encontra-se disponível em http://www.funarte.gov.br/brasilmemoriadasartes/acervo/discosprojeto-almirante/nosso-sinho-do-samba-1988. Acesso em 06/08/2017.
} 
Carvalho e sua equipe de colaboradores na Funarte pertencem a esta vasta rede de relações que se estrutura de forma mais programática, a partir dos anos 1950, quando a velocidade do tempo presente, manifestada na intensificação da circulação de bens, na mudança da paisagem e de valores, é percebida como ameaça aos referenciais de pertencimento.

Foi essa atmosfera de aceleração da história que provocou, nos menos deslumbrados com o devir, um gosto pelo passado, uma nostalgia nem sempre do vivido, de uma época de ouro idealizada como fuga do presente. Desafiados a resistir, atuando em redes, recuperaram e inventaram uma memória coletiva, ideologicamente ancorada no nacionalismo musical, tornando-se seus narradores. Não obstante a política cultural do regime militar tivesse como orientação contemplar a diversidade regional do país, o grupo de Carvalho estabelecido na Funarte, há tempos engajados em torno de um projeto comum, soube estrategicamente abraçar essa oportunidade e oficializar o samba carioca como patrimônio da cultura musical brasileira.

\section{Referências}

BARBOSA, Oreste. Samba: sua historia, seus poetas, seus músicos e seus cantores. Rio de Janeiro. Livraria Educadora, 1933.

BESSA, Virginia. Imagens da escuta: traduções sonoras de Pixinguinha. In MORAES, J.G.V. e SALIBA, E.T. História e Música no Brasil. São Paulo. Editora Alameda, 2010.

BOTELHO, Isaura. Romance de Formação. Funarte e política cultural. Rio de Janeiro. Ministério da Cultura/Edições Casa Rui Barbosa, 2001,

CALABRE, Lia. Políticas Culturais no Brasil: balanço \& perspectivas. In. RUBIM, A. A. C. e BARBALHO, A. (org.) Políticas Culturais no Brasil. Salvador, EDUFBA, 2007.

CARVALHO, Hermínio Bello de. O Canto do pajé: Villa Lobos e a música popular brasileira. Rio de Janeiro: Espaço e Tempo, 1987.

CARVALHO, Hermínio Bello de. Cartas cariocas para Mário de Andrade. Rio de Janeiro. Folha Seca, 1999. 
CARVALHO, Hermínio Bello de. Correspondências Gerais. Dossiê Projeto Lúcio Rangel. CEDOC/FUNARTE. Pasta Eventos Especiais Concurso de Monografias. (1978/1979).

DIAS, Marcia Tosta. Os donos da voz. São Paulo. Boitempo Editorial, 1991.

Dicionário Cravo Albin. Disponível em http://www.dicionariompb.com.br/albino-pinheiro. Acesso em: 22 de julho de 2017.

DOMINGUES, Henrique F oréis. (Almirante). No tempo de Noel Rosa. O Nascimento do Samba e a Era de Ouro da Música Brasileira. Rio de Janeiro. São Paulo. Sonara Edições, 2013.

FERNANDES, Dmitri Cerboncini. Anatomia do gosto da Música Popular Brasileira. $36^{\circ}$ Encontro Anual da ANPOCS, 2012. Disponível em https://anpocs.com/index.php/encontros/papers/36-encontro-anual-da-anpocs/mr3/mro1/8307-anatomia-do-gosto-da-musica-popular-brasileira/file. Acesso em: 15 de agosto de 2017.

GARCIA, Tânia. Tudo bem, e o nacional-popular no Brasil dos anos de 1970. In História, São Paulo, v. 26, n. 2, p. 182-200, 2007.

GARCIA, Tânia. A folclorização do popular. Uma operação de resistência à mundialização da cultura, no Brasil dos anos de 1950. ArtCultura, Uberlândia, v. 12, n. 20, p. 7-22, jan.-jun. 2010

GUIMARÃES, Francisco. Na Roda de Samba. Rio de Janeiro. Typografia São Benedicto, 1933.

LE GOFF, Jacques. História e memória. Campinas. Editora da Unicamp, 2003.

LIRA, Mariza. O Brasil Sonoro: gêneros e compositores populares. Rio de Janeiro: A Noite, 1938.

MARINO, Ian Kisil; MORAES, José Geraldo Vinci de. Notas historiográficas sobre Ary Vasconcelos. In

http://www.memoriadamusica.com.br/site/images/Notas_historiogr\%C3\%A1ficas_sobre_a _obra_de_Ary_Vasconcelos.pdf. Acesso em: 10 de julho de 2017.

MILLARCH, Aramis. Tabloide Digital publicado em 8/04/1980. In http://www.millarch.org/artigo/lucio-rangel-da-nome-para-estimular-mpb . Acesso em: 22 de agosto de 2017. 
MORAES, José Geraldo Vinci de. História e historiadores da música popular no Brasil.

In: Latin American Music Review, v. 28, n², 2007.

MILLARCH, Aramis. Tabloide Digital publicado em 8/04/1980. In

http://www.millarch.org/artigo/lucio-rangel-da-nome-para-estimular-mpb. Acesso em: 10 de julho de 2017.

RANGEL, Lúcio. Sambistas e chorões. São Paulo. Instituto Moreira Sales, 2014.

SIRINELLI, Jean-François. Os Intelectuais. In REMOND, R. Por uma história política. Rio de Janeiro. Fundação Getúlio Vargas, 1996.

PAVAN, Alexandre. Timoneiro. Perfil biográfico de Hermínio Belo de Carvalho. Rio de Janeiro. Casa da Palavra, 2006.

STROUD, Sean. The Defence of Tradition is Brazilian Popular Music. Politics, culture and the creation of música popular brasileira. Ashgate Popular and Folk Music Series. Ashgate Publishing London, 2007.

TINHORÃO, José R. Música Popular, um tema em debate. São Paulo. Editora 34, $3^{\mathrm{a}}$. edição, 1997.

VASCONCELOS, Ary. Panorama da Música Popular Brasileira. Livraria Martins Editora, São Paulo, 1964, 1964. 